\title{
Joseph C. Risser Sr., 1892-1982
}

\author{
M. M. Manring PhD, Jason Calhoun MD
}

Published online: 19 September 2009

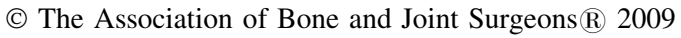

\begin{abstract}
This biographical sketch of Joseph C. Risser Sr. corresponds to the historic text, The Classic: The Iliac Apophysis: An Invaluable Sign in the Management of Scoliosis, available at DOI 10.1007/s11999-009-1096-z.
\end{abstract}

Joseph C. Risser was born August 6, 1892, in Des Moines, Iowa. He earned his medical degree from the University of Iowa in 1923 and served his residency at the New York Orthopedic Hospital [7]. During his residency, he became a protégé of Russell Hibbs, MD (1869-1932), who pioneered spinal fusion for scoliosis patients in the early 20th century [14].

As a resident, Risser began to develop his own innovations in scoliosis treatment, most notably a program for long-term followup of patients. This research effort informed many of his contributions to the treatment of spinal curvatures over more than half a century, almost all of it spent in his practice in Pasadena, California [14].

What became known as the Risser Sign was not the result of a flash of inspiration but rather born from years of hard work and collaboration. Before the 1930s, the

M. M. Manring, J. Calhoun ( $\square)$

Department of Orthopaedic Surgery, The Ohio State University, N1043 Doan Hall, 410 W 10th Ave, Columbus, OH 43210-1228, USA

e-mail: jason.calhoun@osumc.edu

M. M. Manring

e-mail: maurice.manring@osumc.edu relationship between vertebral growth and deformity was not understood. As Risser summarized it in 1966, "One school of thought, including laymen and some of the profession, was that the spinal deformity of scoliosis did not increase after vertebral growth was completed. However, another school of thought, consisting of the specialists, believed that as long as there was motion in the spine, the deformity would increase" [9]. Along with Albert B. Ferguson, MD, another Hibbs' trainee, Risser helped develop radiographic methods still used to assess scoliosis today. According to Wenger [14], Ferguson developed an angular method for measuring $\mathrm{x}$-rays that was invaluable to Risser's observation of the iliac crest.

In 1936, the duo described the progression of scoliosis in untreated patients and noted slow growth of the spine, with gradual increase in deformity between the ages of 5 years and 10 years, and accelerated growth and deformity between the ages of 10 years and 15 years [10]. In 1947, Risser first described his observations regarding the relationship between spinal development and the iliac apophysis at the annual meeting of the American Academy of Orthopaedic Surgeons [2]. By the time he formally published his findings, 11 years later, grading systems based on his observations were in use across the United States.

In the article from 1958 that we reproduce here, Risser describes the well-known sign to assess the state of vertebral growth and predict whether scoliosis curves would progress in growing children. Growth plates in the spine, he noted, are not easily visible and thus could not be used to assess spinal growth with any reliability. However, he observed, the ossification of the iliac apophysis coincided with that of the vertebral plates, and therefore, "the attachment of the iliac apophysis has proved to be an 
excellent physiologic sign to indicate the completion of vertebral growth" [8].

Although the Risser sign has been used widely during the five decades since its description in CORR, controversies remain regarding its accuracy [2, 5, 6]. Many researchers have argued that the estimation of skeletal age through the evaluation of hand and wrist films is a more accurate assessment than the Risser sign $[1,3,11]$. Others believe that a combination of skeletal age and height is the best measurement of remaining growth [12]. Still, the Risser sign and the grading system based on it are most commonly used among pediatric orthopaedists, perhaps because the iliac crest can be immediately evaluated via radiographs, and because of its established relationship to spinal growth over years of use. There are currently two versions of the grading scale [2]; both evaluate the Risser sign and have six grades to assess spinal growth. The version developed in the US divides the iliac crest into quarters, and a system developed by French physicians divides it into thirds (Fig. 1) [2].

Risser found international fame beyond the development of the diagnostic tool that bears his name. In 1961, an Italian senator, Giovanni Leone, contacted Risser to request that he examine Leone's 12-year-old son, Mauro, a polio victim who suffered from a severe curvature of the spine. Risser brought the boy to St. Luke Hospital in Pasadena and performed a spinal fusion, restoring Mauro Leone's ability to stand upright and walk. By 1974, Giovannie Leone had become President of Italy, and that year decorated Risser with the "Cavaliere de Gran Croce dell' Ordine al Merito della Repubblica," or the Grand Cross of Merit, one of several high honors he received from the Italian government [13]. For 22 years, Risser operated an orthopaedic foundation that enabled a total of 52 physicians from across the world (including many Italians) to come to Pasadena and study his methods for a three- to six-month period [7]. He also wrote a book with nutritional guru Adele Davis titled Let's Get Well: A Practical Guide to Renewed Health Through Nutrition [4] and became president of the Academy of Applied Nutrition. He continued his orthopaedic practice in Pasadena until his death in 1982 (see Fig. 2).

The importance of Risser's diagnostic insight is profound, but it may also overshadow the larger lessons of his life and career. His story demonstrates the value of patient, careful observation over a long period of study, collaboration with other experts in the field, and generosity in sharing the fruits of his work with others.
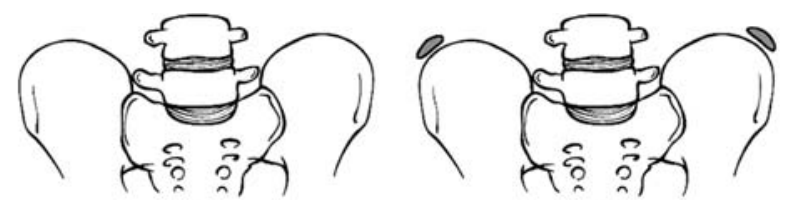

0

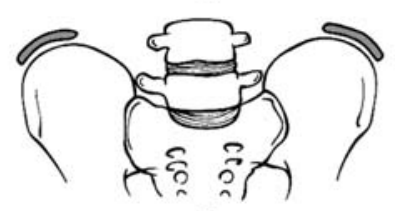

2

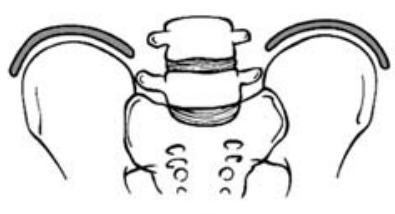

4

A
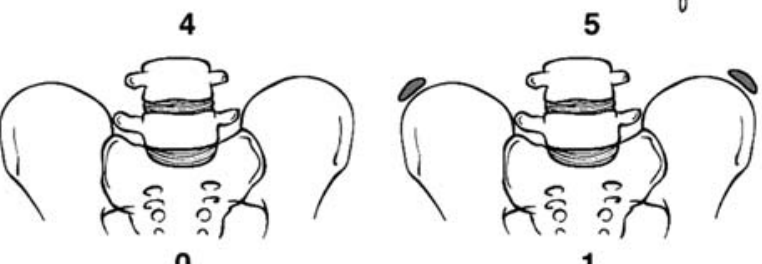

0
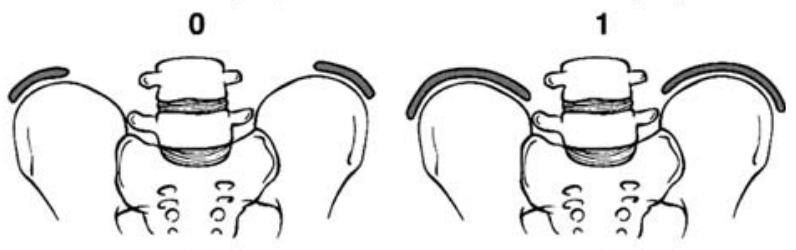

2

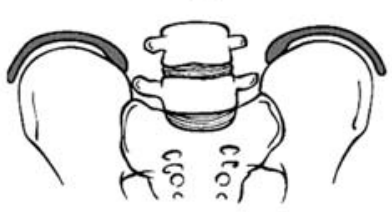

B

4

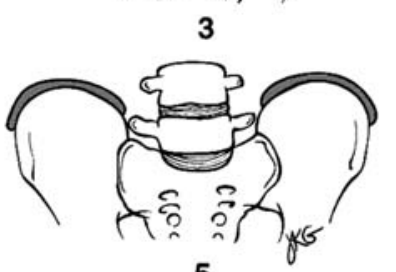

5
Fig. 1A-B The illustrations show the US Risser grading system. (A) The US system comprises six grades. The US Risser 0 is defined as no ossification. The iliac wing is then divided into quarters, defining the first four grades $(1,2,3,4)$ of ossification of the apophysis (capping). The US Risser 5 begins when the ossified apophysis starts fusing to the wing at its posterior extremity. It continues during the whole process of apophysis fusion, which might take as much as 2 years. (B) The French Risser grading system also comprises six stages. French Risser 0 is defined as no ossification. The iliac wing then is divided into thirds, defining the first three grades $(1,2,3)$ of ossification of the apophysis (capping). The fusion of the apophysis to the wing is divided into two grades: Risser 4, when the fusion commences posteriorly, and Risser 5, when the fusion is complete. (Reprinted with permission from Bitan FD, Veliskakis KP, Campbell BC. Differences in the Risser grading systems in the United States and France. Clin Orthop Relat Res. 2005;436:190-195.) 
Fig. 2 Joseph Risser is shown in his college yearbook as a member of Alpha Kappa Kappa. Photograph reprinted with permission from the 1924 Hawkeye Yearbook, Special Collections Department, University of Iowa Libraries, Iowa City, Iowa.

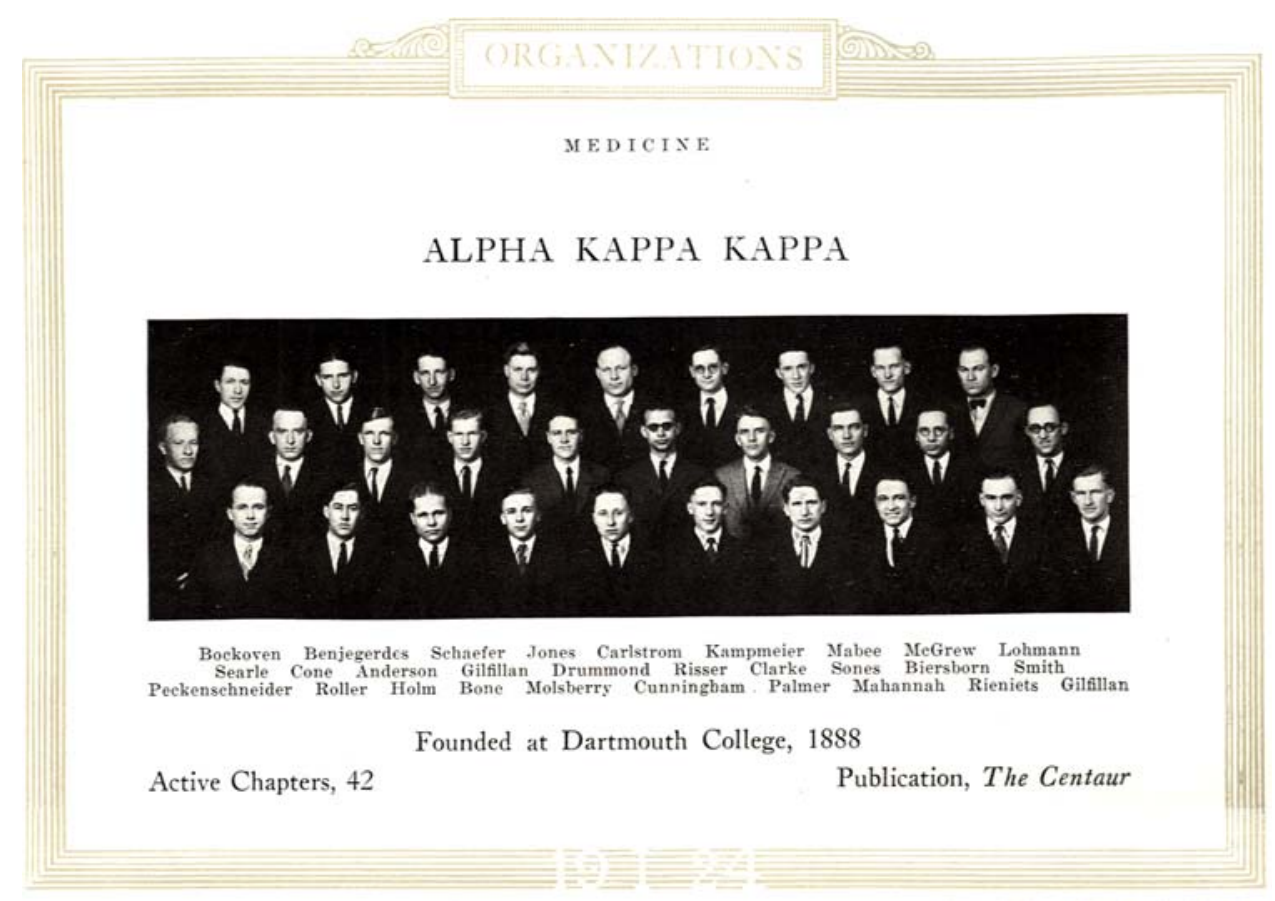

\section{References}

1. Anderson M, Hwang SC, Green WT. Growth of the normal trunk in boys and girls during the second decade of life; related to age, maturity, and ossification of the iliac epiphyses. J Bone Joint Surg Am. 1965;47:1554-1564.

2. Bitan FD, Veliskakis KP, Campbell BC. Differences in the Risser grading systems in the United States and France. Clin Orthop Relat Res. 2005;436:190-195.

3. Calvo IJ. Observations on the growth of the female adolescent spine and its relation to scoliosis. Clin Orthop Relat Res. 1957;10:40-47.

4. Davis A, Risser JC. Let's Get Well: A Practical Guide to Renewed Health Through Nutrition. New York, NY: Harcourt; 1965.

5. Izumi Y. The accuracy of Risser staging. Spine. 1995;20:18681871.

6. Little DG, Sussman MD. The Risser sign: a critical analysis. J Pediatr Orthop. 1994;14:569-575.
7. Pioneer in scoliosis treatment dies. Pasadena Star-News. March 14, 1982:A1, A3.

8. Risser JC. The Iliac apophysis; an invaluable sign in the management of scoliosis. Clin Orthop Relat Res. 1958;11:111-119.

9. Risser JC. Treatment of scoliosis during the past 50 years. Clin Orthop Relat Res. 1966;44:109-113.

10. Risser JC, Ferguson AB. Scoliosis: its prognosis. J Bone Joint Surg Am. 1936;18:667-670.

11. Roche AF, Eyman SL, Davila GH. Skeletal age prediction. $J$ Pediatr. 1971;78:997-1003.

12. Shuren N, Kasser JR, Emans JB, Rand F. Reevaluation of the use of the Risser sign in idiopathic scoliosis. Spine. 1992;17: 359-361.

13. Swaim D. Highest Italian Award. Pasadena Star-News. Jan. 13, 1974:A1.

14. Wenger DR. Children's Orthopaedics in North America - History, Genealogy, and Evolution. Rosemont, IL.: Pediatric Orthopaedic Society of North America; 2006. 